\title{
Polyoxyl 60 Hydrogenated Castor Oil
}

National Cancer Institute

\section{Source}

National Cancer Institute. Polyoxyl 60 Hydrogenated Castor Oil. NCI Thesaurus. Code C84660.

A polyethylene glycol derivative of hydrogenated castor oil where the average PEG chain length is 60 . PEG-60 hydrogenated castor oil is a nonionic surfactant used as an emulsifying and solubilising agent in pharmaceutical preparations and cosmetics. 